\title{
IDENTIFICATION PLASTIC BOTTLE BASED ON LIGHTING SYSTEM
}

\author{
JHOSUA ARIE SWANDI, IRSYADI YANI* \\ Mechanical Engineering Department, Sriwijaya University, South Sumatera, Indonesia \\ *Corresponding author: irsyadiyani@ft.unsri.ac.id
}

(Received: 1 October 2020; Accepted: 13 November 2020; Published on-line: 31 November 2020)

\begin{abstract}
The challenge in waste sorting systems such as plastic bottles is how to identify and classify the types of it. This work aims to build a system of identification and classification of sorting plastic bottles by type. This system uses the Backpropagation method by utilizing a webcam to get colors in the form of Red, Green, and Blue (RGB) color spaces. As light control, three types of lights are used, blue, red, and yellow. The three types of plastics that will be identified are PET, HDPE, and PP. The conclusion from this work is that the percentage of success is $18 \%, 28 \%$, and 42 for yellow, blue, and red lighting, respectively.
\end{abstract}

KEYWORDS: Sorting, Plastic Bottles, RGB, and Lighting

\section{INTRODUCTION}

The use of plastic in the world every year continues to increase. Within 4 years the use of plastic in the world has increased by $24.4 \%$ and in 2010 the use of world plastic reached 225 billion kilograms [1]. Plastic materials have advantages over other materials, that are strong, lightweight, difficult to break, have good formability, and can conduct heat and electricity well. However, plastic materials that accumulate will become garbage and then cause harm to the environment because plastic waste has a fairly slow decomposition process [2]. This makes the recycling process the right action in managing plastic waste. The process of recycling plastic waste can make this plastic waste into new items that can be reused so that it can reduce the growth of environmental pollution [3]. To recycle plastic sorting based on the type of resin that is formed by using a machine and inexpensive, it can be obtained recycled results that can save costs and have added value [4].

Plastics can be grouped according to the type of resin forming it which is recycled to be marked with a number to facilitate the sorting, namely code number 1 for the type of Polyethylene Terephthalate (PET / PETE), code number 2 for the type of High-Density Polyethylene (HDPE), code number 3 for the type of Polyvinyl Chloride (PVC), code number 4 for the type of Low-Density Polyethylene (LDPE), code number 5 for the type of Polypropylene (PP), code number 6 for the type of Polystyrene (PS), and code number 7 for the type Other $(\mathrm{O})$ [5]. The sorting system that involves human hands to the sorting system operated by computer vision is a method used to sort plastic so that it can be processed to the next stage [6]. The sorting system that involves human hands has several obstacles in the form of relatively high processing costs, inconsistent quality of the final product, and inefficient sorting. For the sake of achieving safe, clean, and efficient recycling results, it is necessary to automate this plastic waste sorting system [7]. 
Image processing is an image processing that uses computer vision so that the image quality is better so that it can be easily interpreted by the computer [8]. Image processing methods can be used to automate the sorting system. Digital devices are needed to identify the type of plastic bottle as an image catcher. The webcam is one of the digital devices used in this study as image capture. Backpropagation is a method of artificial neural network that can train the network so that it gets the balance of the ability of the network to recognize the pattern [9]. The results of pattern recognition are used during the training. This artificial neural network can provide the correct response to the same input pattern as the pattern used during training [10].

The processing of plastic bottle waste in the recycling process has one stage which is very influential in the subsequent stages so that it runs well. This stage is the sorting stage. At the stage of sorting is still done manually by humans. The manual process is inefficient and ineffective for large amounts of plastic bottles. That the author has the desire to research by making automation of identification of plastic bottles using lighting system based on the type of resin that is assisted with a webcam as image processing and processed with computer vision so that humans can easily carry out the sorting stage automatically.

\section{METHOD}

Brief and representative performances are used to display the design or research design and the methods used. Overall the detection flow diagram is shown in Fig. 1.

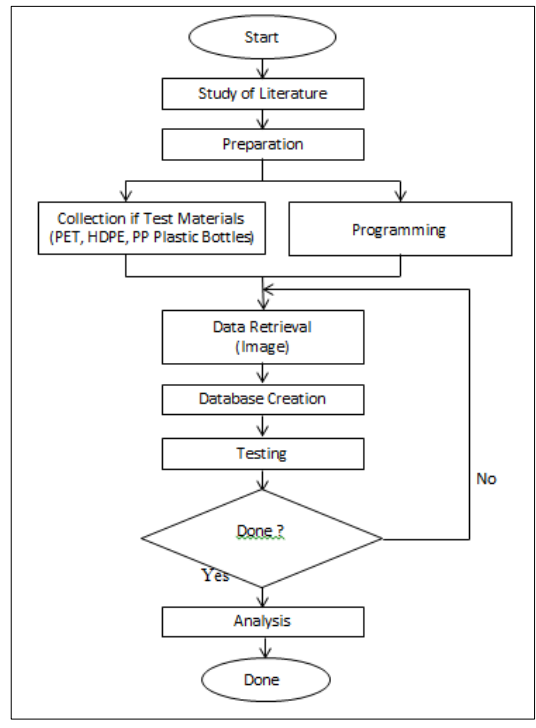

(a)

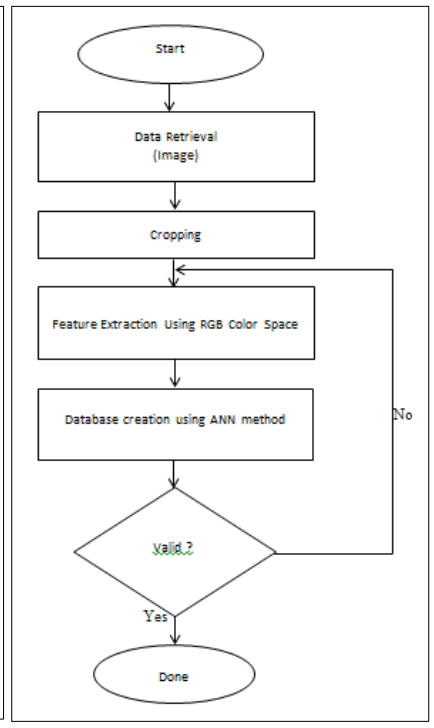

(b)

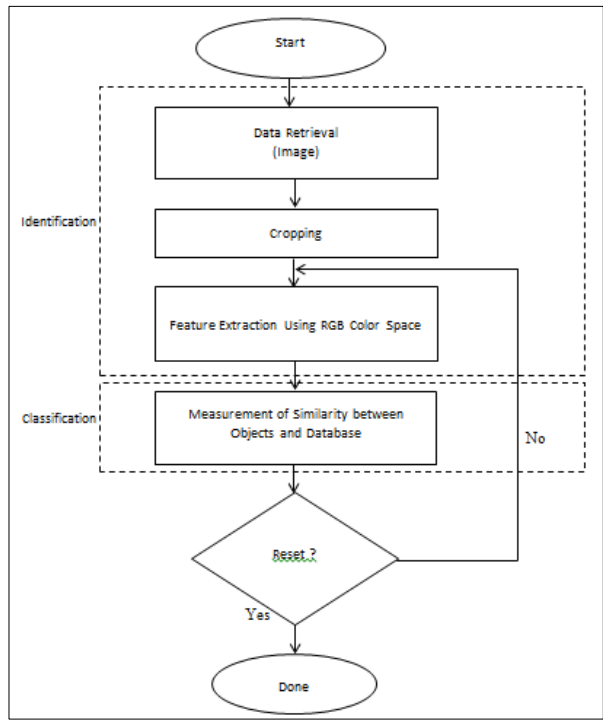

(c)

Fig. 1. (a)Research Flowchart, (b)Database Creation Flowchart (c)Flowchart of Identification and Classification

\subsection{Design Experiment}

The identification and classification system of plastic bottles have the main components, namely webcam, and computer. The webcam has a function to capture digital images automatically from objects, in this case is a plastic bottle. Digital images taken by webcam are then processed on a computer system for identification and classification. The design experimental of the identification and classification system can be seen in Fig. 2. 


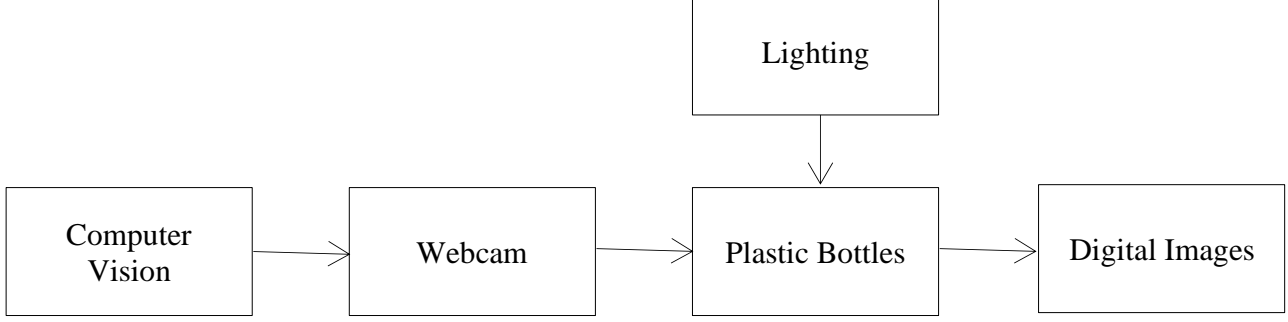

Fig. 2. Design Experiment of identification and classification system

\subsection{Image Pre-Processing}

The image in this study in the form of photos or images of fruit taken from three positions, namely horizontal, vertical, and tilted positions. Lighting is carried out using static blue, red, and yellow LED lights on each image capture. The image of the plastic bottle is not blocked by any object, because it will interfere with the quality of the image. Image format in the form of ".jpg". The image of a plastic bottle must have good image quality.

Table 1. Examples image of PET, HDPE and PP plastic bottles in horizontal, tilted, and vertical positions in blue LED lighting

\begin{tabular}{|c|c|c|c|}
\hline Image & Horizontal & Tilted & Vertical \\
\hline PET type & & & \\
\hline plastic bottles & be: a & & \\
\hline HDPE type & & & \\
\hline plastic bottles & $\varnothing$ & & L \\
\hline PP type plastic & & & \\
\hline bottles & $\mapsto$ & a & 1 \\
\hline
\end{tabular}

Table 2. Examples image of PET, HDPE and PP plastic bottles in horizontal, tilted, and vertical positions in red LED lighting

\begin{tabular}{llll}
\hline \multicolumn{1}{c}{ Image } & Horizontal & Tilted & Vertical \\
\hline PET type & & & \\
plastic bottles & & & \\
& & & \\
HDPE type & & & \\
plastic bottles & & &
\end{tabular}


PP type plastic

bottles
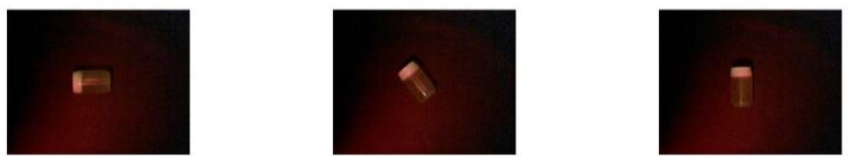

Table 3. Examples image of PET, HDPE and PP plastic bottles in horizontal, tilted, and vertical positions in yellow LED lighting

\begin{tabular}{llll}
\hline \multicolumn{1}{c}{ Image } & Horizontal & Tilted & Vertical \\
\hline $\begin{array}{l}\text { PET type } \\
\text { plastic bottles }\end{array}$ & & & \\
HDPE type & & & \\
plastic bottles & & & \\
PP type plastic & & & \\
bottles & & & \\
\hline
\end{tabular}

\subsection{Feature Extraction}

The images that have been collected have a lot of 810 consisting of 90 images in each type of PET, HDPE, and PP plastic waste with each red, blue and yellow LED lighting. The captured image is then collected and saved in the ".jpg" file format. In extracting the contour of the object, the edge detection algorithm in the form of cropping aims to obtain a more detailed and focused image characteristic. The image stored in the database has a size of $560 \times 420$ pixels. In getting the characteristics of a more detailed and focused image, template extraction is done with a size of $34 \times 34$ pixels. The results of cropping are done by taking a piece of the image in the middle of the image as shown in Fig 3.

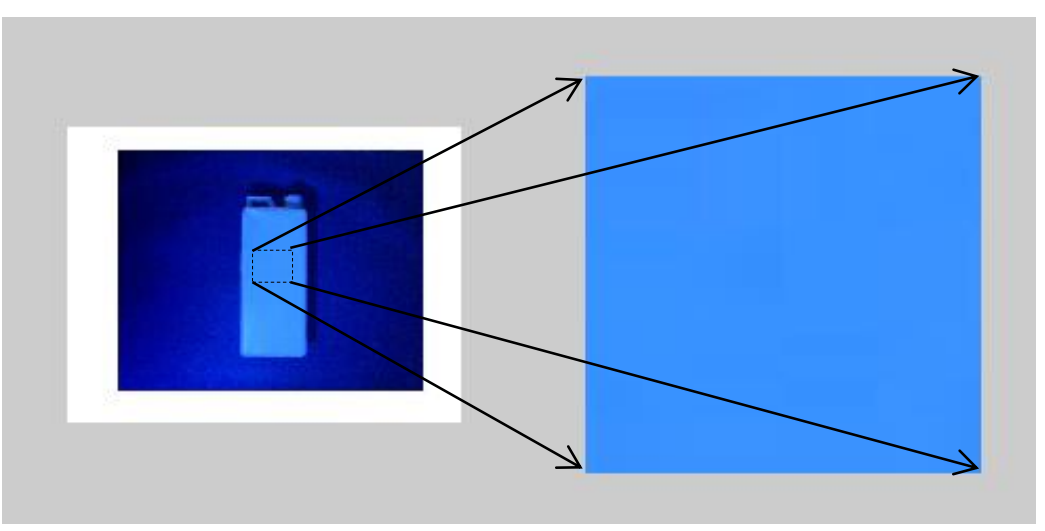

Fig. 3. The results of cropping on one image

An image processing process that is carried out to recognize objects that are in the image with parameters that can characterize an object can be called feature extraction. Feature extraction has a way of working by distinguishing an object from one object to another 
significantly. Shape characteristics, size characteristics, texture characteristics, geometric features, and color characteristics are various types of features that can be used as a classification or classification of an object. The characteristics of each object are extracted based on certain parameters and grouped into certain classes. For example to characterize the color of an object that is included in the RGB color class (Red, Green, Blue) then the parameters used in red, green, and blue.

In the process of identification and classification required values generated from the parameters that have been determined are used as input data in its processing. An object that is used by an object with other objects must be determined precisely in advance, if the acquired features do not characterize an object with complexity, then the recognition of complex patterns cannot be carried out. Color space is the result of representing a color segmentation processing. There are several known color spaces, including RGB (Red, Green, Blue), HSV (Hue, Saturation, Value), YcbCr, etc.

This study using the RGB color space (Red, Green, Blue). RGB color space is a color space that has three main colors, namely red, green, and blue. RGB color space can be represented in a three-dimensional cartesian diagram, where the combination of each color value combination can form a variety of different colors. The color values in the RGB color space are between $0-255$, so each color has 256 color levels. In a three-dimensional cartesian diagram usually represented by three coordinate axes, namely the $\mathrm{x}$-axis, $\mathrm{y}$-axis, and $\mathrm{z}$-axis, then produce a vector $\mathrm{r}=(\mathrm{x}, \mathrm{y}, \mathrm{z})$. A 3-dimensional cartesian diagram for the RGB color space can be seen as shown in Figure 4. Each axis represents each color in the RGB color space. For example red vector $=\operatorname{RGB}(255,0,0)$; green color $=\operatorname{RGB}(0,255,0)$; blue color $=$ RGB $(0,0,255)$; etc.

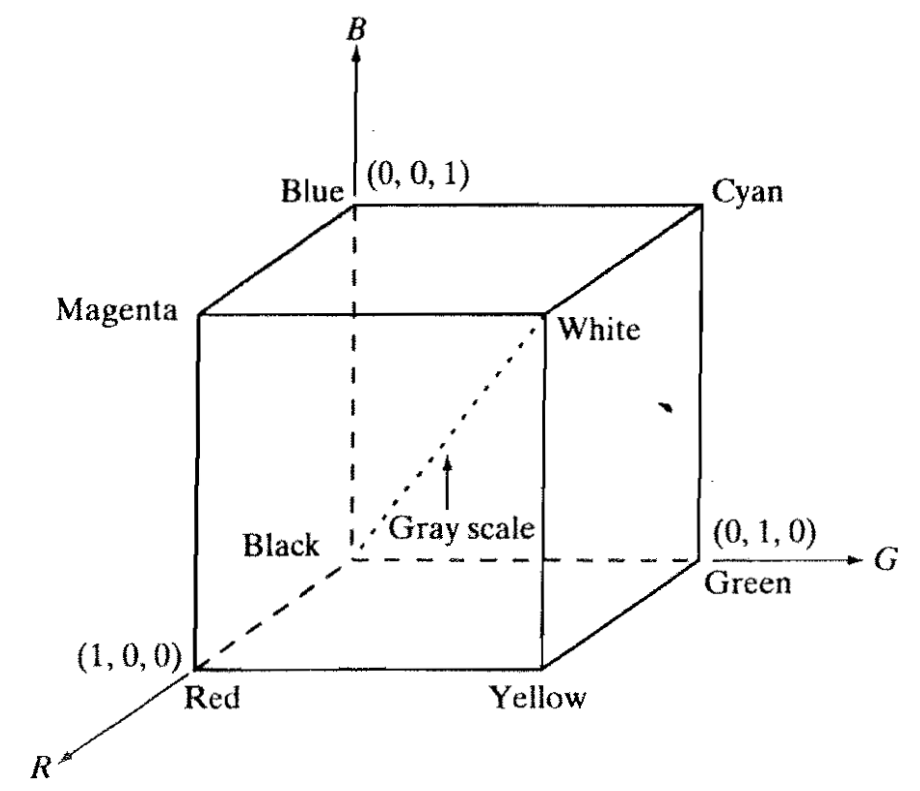

Fig. 4. Three Dimensional Cartesian Diagram for RGB Color Space [11]

\subsection{Database}

Making a database aims to save features that have been obtained from the process of image capture and feature extraction. Some of the processes carried out in making a database include image processing, feature extraction, identification, and classification [12]. The process before image processing includes image acquisition and feature extraction which 
contains cropping and image color extraction. The cropping process consists of matching templates as well as the RGB color space extraction process [13]. The classification process is done by matching image data which will be identified with image data that has been stored in a database. RGB values are made in graphical form so that it becomes easier to observe and analyze. The steps to create a database are summarized in Fig. 5.

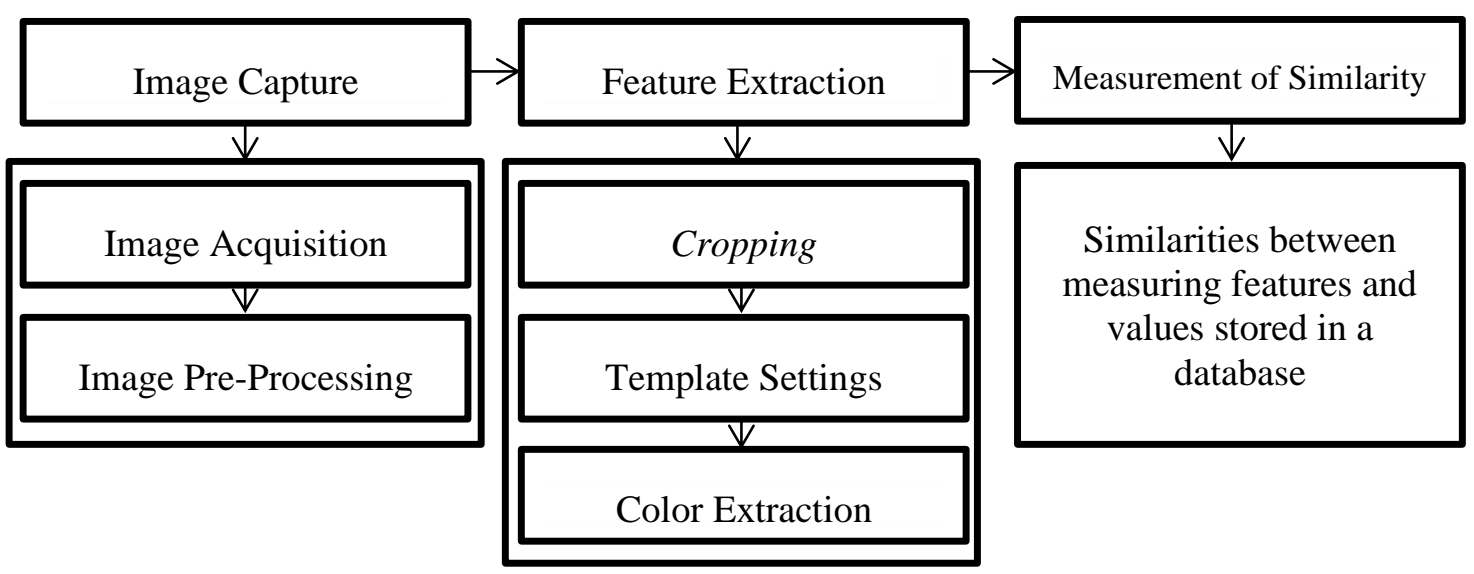

Fig. 5. The steps to create a database

\section{RESULTS AND DISCUSSION}

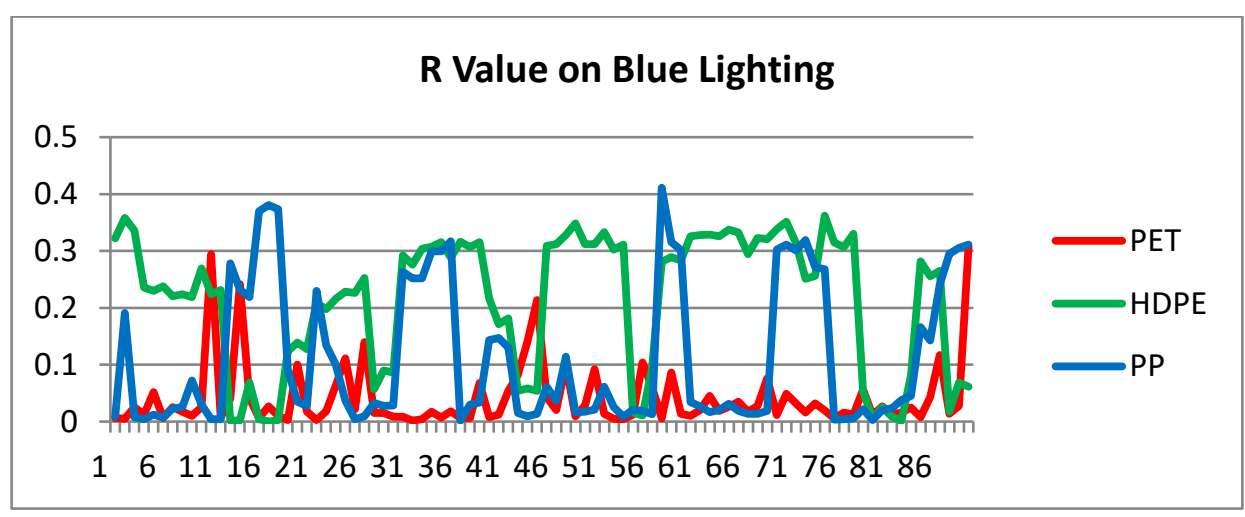

Fig. 6. Graph of R-value on the type of plastic waste PET, HDPE, and PP blue lighting

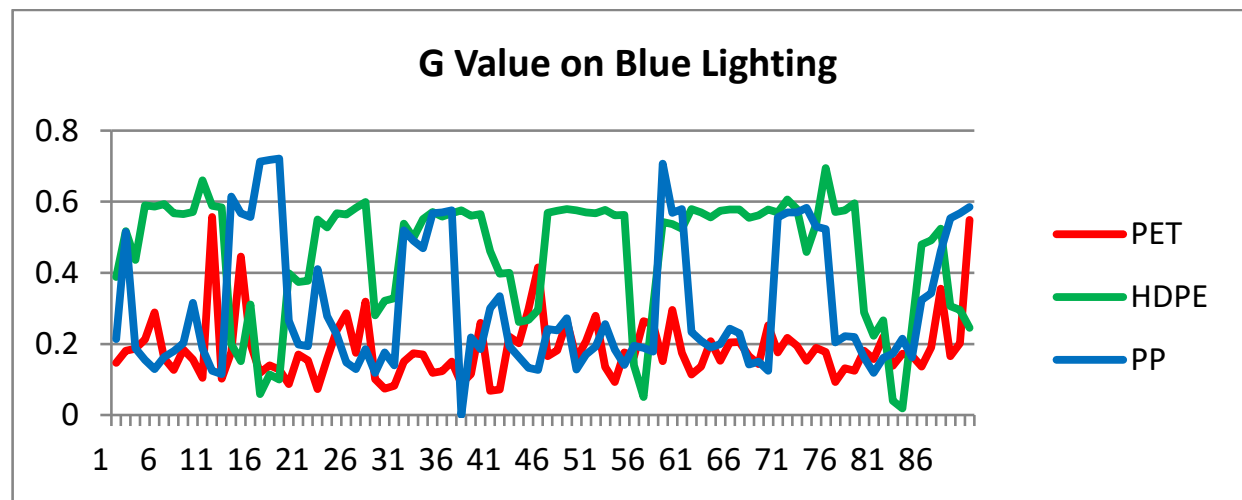

Fig. 7. Graph of G-value on the type of plastic waste PET, HDPE, and PP blue lighting 


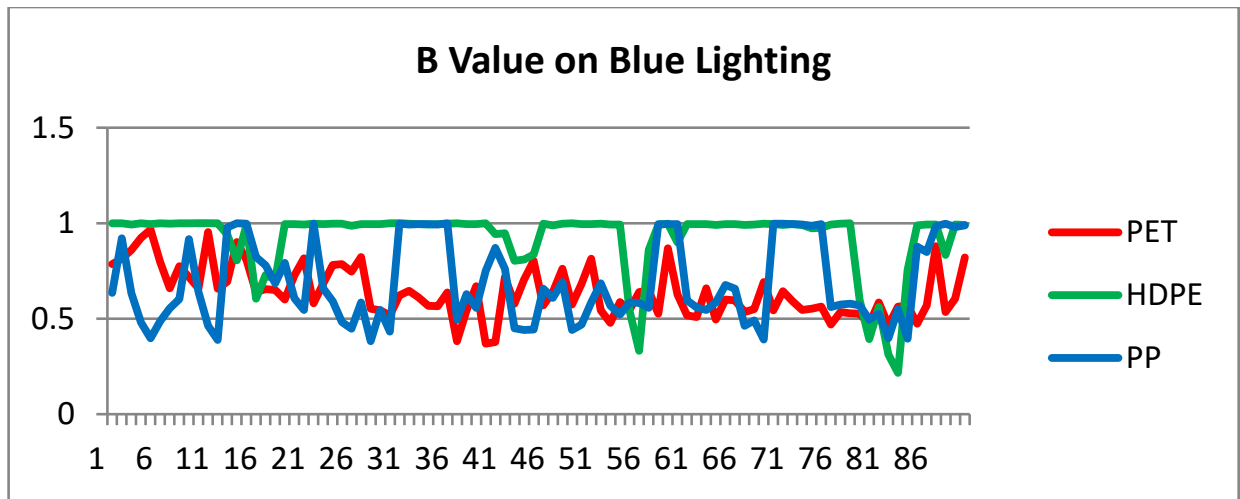

Fig. 8. Graph of B value on the type of plastic waste PET, HDPE, and PP blue lighting

On the blue light, PP plastic bottles have the highest R, G, and B values among the other types of plastic bottles as shown in Fig. 6, Fig. 7, Fig. 8. From this graph, PET plastic bottles with blue lighting have a maximum Red value of 0.3076 and a minimum of 0.0017 , a maximum Green value of 0.557 , and a minimum of 0.0681 and a maximum Blue value of 0.9663 and a minimum of 0.3691 . HDPE plastic bottles with blue lighting have a maximum Red value of 0.362 and a minimum of 0.0001 , a maximum Green value of 0.6946 and a minimum of 0.0185 , and a maximum Blue value of 1 and a minimum of 0.2162 . PP plastic bottles with blue lighting have a maximum Red value of 0.4111 and a minimum of 0.0016 , a Green value of a maximum of 0.7213 and a minimum of 0.1153 , and a maximum Blue value of 0.9998 and a minimum of 0.3821 .

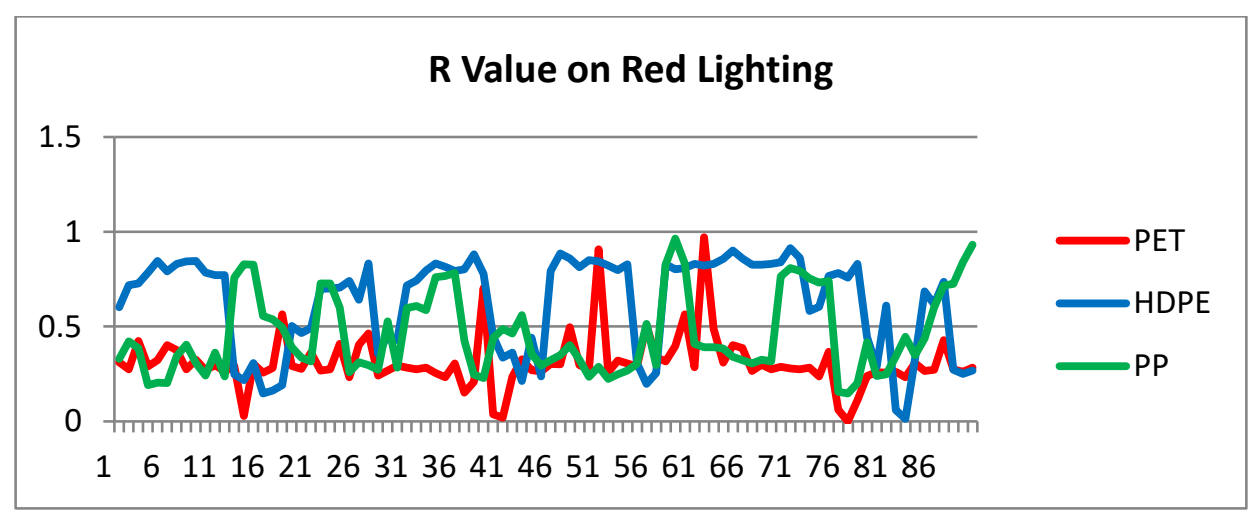

Fig. 9. Graph of R-value on the type of plastic waste PET, HDPE, and PP red lighting

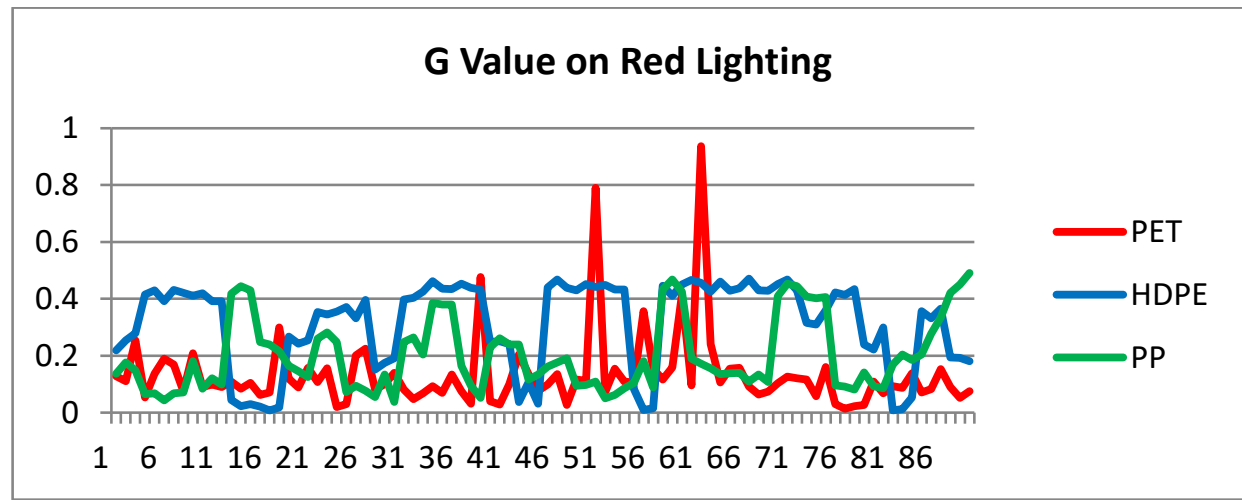

Fig. 10. Graph of G-value on the type of plastic waste PET, HDPE, and PP red lighting 


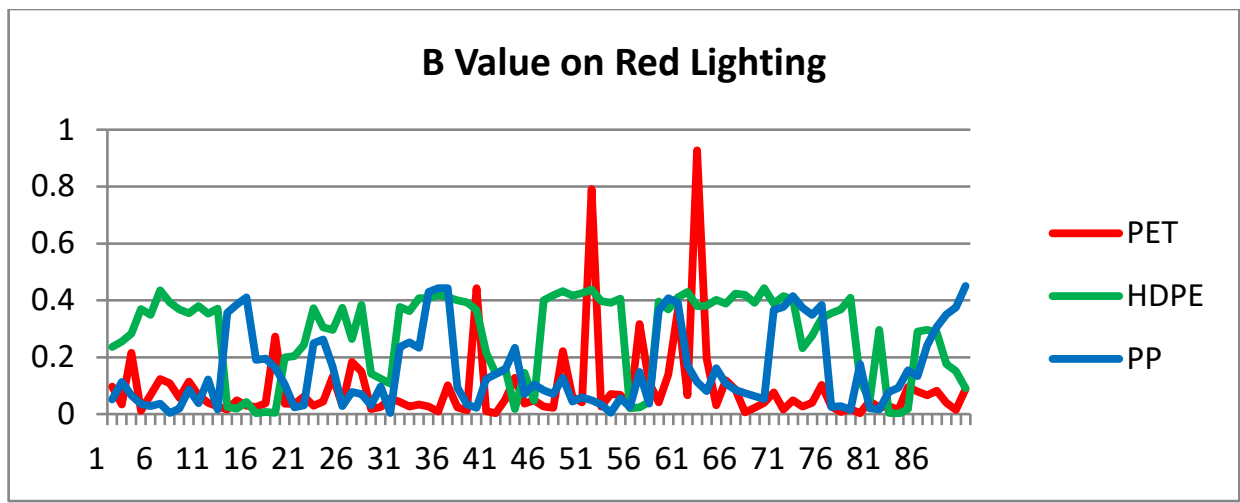

Fig. 11. Graph of B-value on the type of plastic waste PET, HDPE, and PP red lighting

On the red light, PET plastic bottles have a value of $\mathrm{R}$ respectively, $\mathrm{G}$ and $\mathrm{B}$ are the biggest among the other types of plastic bottles as shown in Fig. 9, Fig. 10, Fig. 11. From the graph, PET plastic bottles with red lighting have a maximum Red value of 0.9713 and a minimum of 0.0207, a Green value of a maximum of 0.9369 , and a minimum of 0.0138 and a maximum Blue value of 0.9272 and a minimum of 0.003 . HDPE plastic bottles with red lighting have a maximum Red value of 0.9137 and a minimum of 0.0135 , a maximum Green value of 0.4711 and a minimum of 0.0077 , and a maximum Blue value of 0.4428 and a minimum of 0.0006 . PP plastic bottles with red lighting have a maximum Red value of 0.9642 and a minimum of 0.1471 , a maximum Green value of 0.4911 and a minimum of 0.0376 , and a maximum Blue value of 0.4504 and a minimum of 0.0039 .

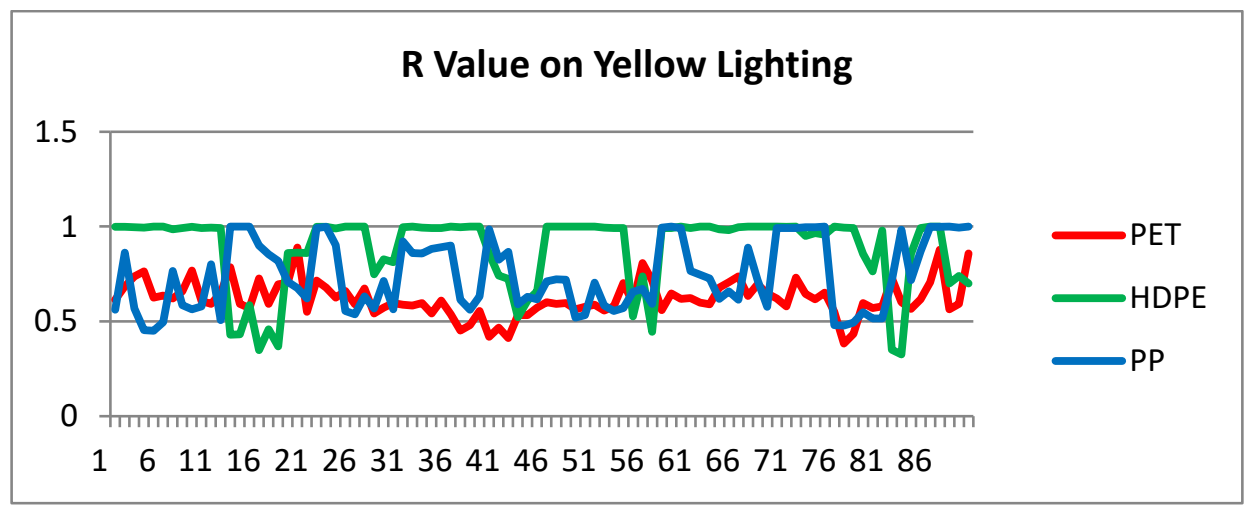

Fig. 12. Graph of R-value on the type of plastic waste PET, HDPE, and PP yellow lighting

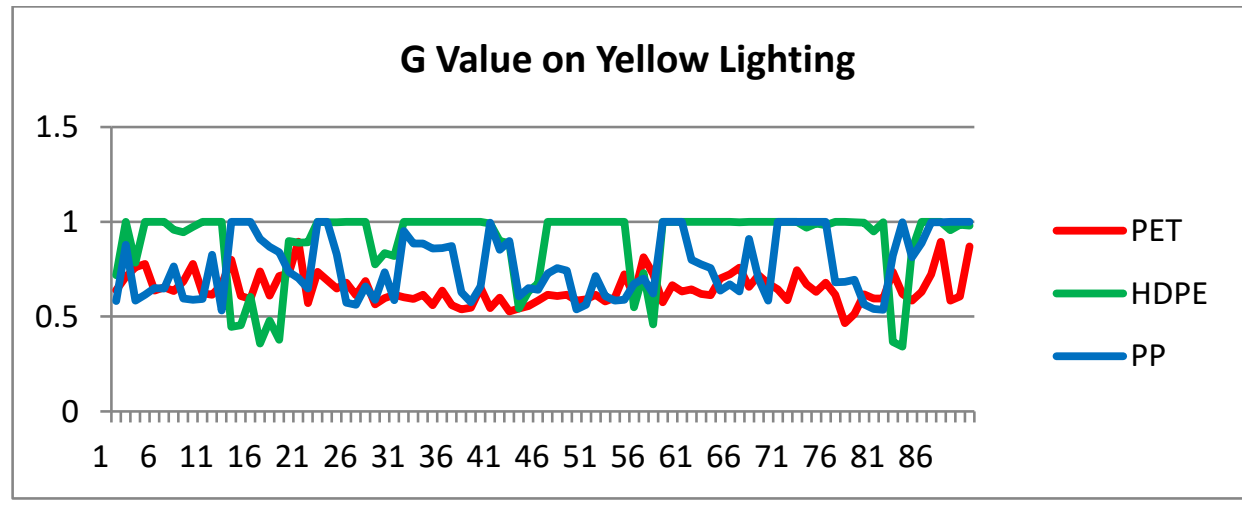

Fig. 13. Graph of G-value on the type of plastic waste PET, HDPE, and PP yellow lighting 


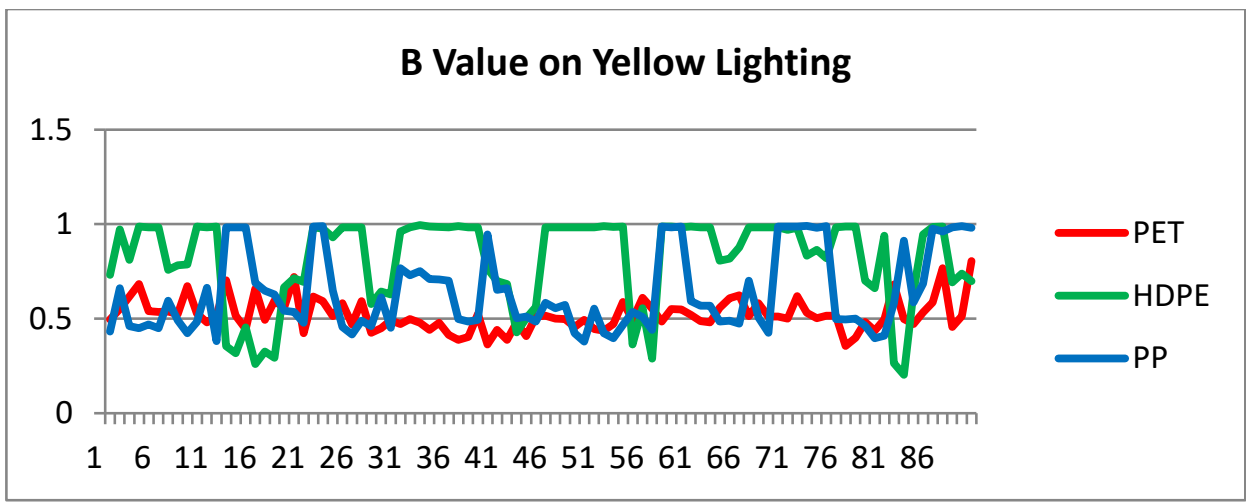

Fig. 14. Graph of B-value on the type of plastic waste PET, HDPE, and PP yellow lighting

On the yellow light, PP plastic bottles have the value of each R, G, and B is the biggest among other types of plastic bottles as shown in Fig. 12, Fig. 13, Fig 14. From this graph, PET plastic bottles with yellow lighting have a maximum Red value of 0.8896 and a minimum of 0.3831 , a Green value of a maximum of 0.8954 , and a minimum of 0.4656 , and a Blue value of a maximum of 0.805 and a minimum of 0.3558 . HDPE plastic bottles with yellow lighting have a maximum Red value of 1 and a minimum of 0.3258 , a maximum Green value of 1 and a minimum of 0.3418 , and a Blue value of a maximum of 0.9953 and a minimum of 0.2031 . PP plastic bottles with yellow lighting have a maximum Red value of 1 and a minimum of 0.4505 , a maximum Green value of 1 and a minimum of 0.5325 , and a Blue value of a maximum of 0.9909 and a minimum of 0.379 .

\section{CONCLUSION}

In this study identification of PET, HDPE and PP plastic bottles with red, blue and yellow LED lighting systems. Identification using the RGB method with a database derived from image capture in the form of image acquisition and image pre-processing and feature extraction in the form of template settings, cropping, and color extraction. Lighting comparison using red, blue, and yellow LED lights to identify and classify PET, HDPE and PP plastic bottles found that the yellow LED lights to produce higher average R, G, and B values than the other two colored LED lights. In the identification testing process using 50 samples of plastic bottles with blue, red, and yellow lights, each obtained a percentage of success of $18 \%, 28 \%$, and $42 \%$.

\section{ACKNOWLEDGEMENT}

Thanks to Universitas Sriwijaya to facilities and as funder this research.

\section{REFERENCES}

[1] A. Rahmawati, "Perbandingan Penggunaan Polypropilene (Pp) Dan High Density Polyethylene (Hdpe) Pada Campuran Laston_Wc," J. Media Tek. Sipil, vol. 15, no. 1, p. 11, 2017.

[2] U. B. Surono and I. Ismanto, "The new law journal," J. Mek. dan Sist. Termal, vol. 1, no. 1, pp. 32-37, 2008.

[3] O. Kehinde, O. J. Ramonu, K. O. Babaremu, and L. D. Justin, "Plastic wastes: environmental hazard and instrument for wealth creation in Nigeria," Heliyon, vol. 6, no. 10, 2020.

[4] S. R. Ahmad, "A new technology for automatic identification and sorting of plastics for recycling," Environ. Technol., vol. 25, no. 10, pp. 1143-1149, 2004.

[5] U. B. Surono, "Various Plastic Waste Conversion Methods Become Oil Fuel," e-journal 
Janabadra, pp. 32-40, 2014.

[6] E. Scavino, M. A. M. Arebey, H. Basri, A. Hussain, M. A. Hannan, and R. M. Saleh, "A Computer vision based experimental device for plastic bottle identification and sorting," CivilComp Proc., vol. 92, 2009.

[7] I. Yani and I. Budiman, "Development of identification system of cans and bottle," J. Phys. Conf. Ser., vol. 622, no. 1, 2015.

[8] R. Munir, Pengantar Pengolahan Citra. Bandung: ITB, 2006.

[9] S. P. Siregar and A. Wanto, "Analysis of Artificial Neural Network Accuracy Using Backpropagation Algorithm In Predicting Process (Forecasting)," IJISTECH (International J. Inf. Syst. Technol., vol. 1, no. 1, p. 34, 2017.

[10] E. P. Cynthia and E. Ismanto, "Jaringan Syaraf Tiruan Algoritma Backpropagation Dalam Memprediksi Ketersediaan Komoditi Pangan Provinsi Riau,” pp. 2579-5406, 2017.

[11] R. E. Gonzalez, Rafael C dan Woods, Digital Image Processing Third Edition, 3rd ed. Pearson Education International, 2018.

[12] G. Kumar and P. K. Bhatia, "A detailed review of feature extraction in image processing systems," Int. Conf. Adv. Comput. Commun. Technol. ACCT, vol. 5, no. 1, pp. 5-12, 2014.

[13] F. A. I. Achyunda Putra, F. Utaminingrum, and W. F. Mahmudy, "HOG Feature Extraction and KNN Classification for Detecting Vehicle in The Highway," IJCCS (Indonesian J. Comput. Cybern. Syst., vol. 14, no. 3, p. 231, 2020. 